\title{
Analysis of high predicted pulmonary function: possibility of overestimation in small elderly examinees
}

Youjin Chang ${ }^{1,}$, Ho Cheol Kim ${ }^{2, *}$, Kyung-Wook Jo ${ }^{2}$, Jae Seung Lee ${ }^{2,3}$, Yeon-Mok Oh ${ }^{2,3}$, Sang Do Lee ${ }^{2,3}$, and Sei Won Lee ${ }^{2,3}$

\author{
${ }^{1}$ Division of Pulmonary and Critical \\ Care Medicine, Department of \\ Internal Medicine, Inje University \\ Sanggye Paik Hospital, Seoul; \\ ${ }^{2}$ Department of Pulmonary and \\ Critical Care Medicine and ${ }^{3}$ Clinical \\ Research Center for Chronic \\ Obstructive Airway Diseases, Asan \\ Medical Center, University of Ulsan \\ College of Medicine, Seoul, Korea \\ Received: August 15, 2018 \\ Revised : October 29, 2018 \\ Accepted: November 12, 2018

\section{Correspondence to} \\ Sei Won Lee, M.D. \\ Department of Pulmonary and \\ Critical Care Medicine and Clin- \\ ical Research Center for Chronic \\ Obstructive Airway Diseases, Asan \\ Medical Center, University of Ul- \\ san College of Medicine, 88 Olym- \\ pic-ro 43-gil, Songpa-gu, Seoul \\ 05505, Korea \\ Tel: $+82-2-3010-3990$ \\ Fax: +82-2-3010-6968 \\ E-mail:iseiwon@gmail.com
}

Background/Aims: Few studies have attempted to interpret unusually high predicted pulmonary function test results. This study aimed to investigate the demographic features of patients with an unusually high predicted pulmonary function.

Methods: The demographic data of subjects who underwent pulmonary function testing at a tertiary referral hospital during between January 2011 and December 2011 were retrospectively reviewed.

Results: Of the 68,693 included patients, 55 (0.08\%) had a percent predicted forced expiratory volume in 1 second or forced vital capacity $\geq 140 \%$. These patients had a relatively older median age ( 72 years vs. 54 years, $p<0.001$ ), female predominance $(65.5 \%$ vs. $42.5 \%, p=0.001)$, lower body weight $(52.5 \mathrm{~kg}$ vs. $64.5 \mathrm{~kg}, p<0.001)$ and shorter height $(148.4 \mathrm{~cm}$ vs. $164.2 \mathrm{~cm}, p<0.001)$. Furthermore, $6.1 \%$ of women older than 80 years with weight $<50 \mathrm{~kg}$ and height $<150 \mathrm{~cm}$ had a high predicted pulmonary function.

Conclusions: A high predicted pulmonary function is not rare among elderly subjects with a small body size. Physicians should consider the demographics of the examinees, especially those of minority populations, particularly as the test results might be determined using an incorrect reference equation.

Keywords: Pulmonary function test; Spirometry; Forced expiratory volume; Forced vital capacity

*These authors contributed equally to this work.

\section{INTRODUCTION}

The pulmonary function test (PFT) is an important tool used to identify and monitor patients with respiratory disease. This test reveals the statuses of the small and large airways and the integrity of the pulmonary parenchyma [1]. Although the PFT itself is not diagnostic, an abnormal result can help establish confirmative diagno- ses of many respiratory diseases when combined with the patient's history. The PFT also helps to predict the risk and prognosis associated with lung resection [2]. Chronic obstructive pulmonary disease can be diagnosed using the ratio of forced expiratory volume in 1 second (FEV1) and the forced vital capacity (FVC) [3]. Furthermore, improvement of $\mathrm{FEV}_{1}$ is an important target of asthma treatments [4]. The PFT results therefore pro- 
vide important information about these major chronic respiratory diseases.

Abnormal spirometry is usually defined as an $\mathrm{FEV}_{1}$, $\mathrm{FVC}$, or $\mathrm{FEV}_{1} / \mathrm{FVC}$ value below the normal range. Although unusually high values may also be encountered during PFT, the clinical meaning of this type of abnormality has not been evaluated and is not usually mentioned in the guidelines. Only one guideline briefly comments on the unusual nature of a percent predicted value $>140 \%$ and instructs clinicians to ensure that the employee's age or height has been measured and entered correctly in such cases. If the unusually high percent predicted value cannot be explained by an error, the guideline recommends recalibration of the spirometer [5].

One might assume that such unusually high spirometry values merely represent a few exceptional cases, mistakes in the input of demographic data, or calibration errors. The reference equations were developed using data collected from representative healthy populations. In other words, the references for minority populations, such as people with unusual heights and weights or ages $>80$ years, are based on small numbers of subjects or extrapolations $[6,7]$. We therefore hypothesized that the reference equations might not be sufficiently accurate, and this limitation could lead to the underestimation of predicted values in some minority populations. Therefore, an unusually high predictive value may be possible in specific groups and should not be considered merely an error of demographics or calibration. This study aimed to characterize the demographic features of subjects with a high percent predicted pulmonary function value.

\section{METHODS}

\section{Study design and participants}

Adults aged $\geq 18$ years who underwent PFT at the Asan Medical Center between January and December 2011 were considered eligible. The subjects' demographic and PFT data were collected by a review of the medical records. The Institutional Review Board of Asan Medical Center approved this study (study number: 20130221) and waived the need for informed consent. This study had no impact on patient management.

\section{Pulmonary function test}

Spirometry was conducted by specially trained pulmonary technicians who used a digital computed spirometer (Sensomedic, Anaheim, CA, USA) according to the recommendations of the American Thoracic Society [8]. At least three spirometry maneuvers were performed, and the best measures were recorded. The predicted $\mathrm{FEV}_{1}$ and FVC were derived from the survey data of a population of lifetime non-smoking participants with normal chest radiographs and no history of respiratory diseases or symptoms [7]. The high pulmonary function group comprised subjects with a predicted $\mathrm{FEV}_{1}$ or $\mathrm{FVC}$ of $\geq 140 \%$.

\section{Statistical analysis}

Continuous variables are reported as medians $25 \%$ to $75 \%$ interquartile ranges [IQRs]) or means \pm standard deviations, and categorical variables are reported as numbers (percentages). SPSS version 18.0 (SPSS Inc., Chicago, IL, USA) was used for the statistical analysis. Student's $t$ test and Fisher's exact test were used to compare continuous and categorical variables, respectively. For each variable, a univariate analysis was performed using a binary logistic regression; the statistically significant variables were then included in a multivariate analysis. For two-tailed tests, a $p$ value of $<0.05$ indicated statistical significance.

\section{RESULTS}

\section{Subjects' characteristics}

A total of 68,693 eligible subjects were tested during the study period; of them, 29,224 (43\%) were female. The median age was 54 years (IQR, 46 to 63). The mean height, body weight and body mass index (BMI) were 164.3 \pm $8.7 \mathrm{~cm}, 63.9 \pm 11.5 \mathrm{~kg}$, and $23.7 \pm 3.2 \mathrm{~kg} / \mathrm{m}^{2}$, respectively. Among male subjects, the mean height, body weight, and BMI were $169.6 \pm 6.3 \mathrm{~cm}, 70.0 \pm 10.4 \mathrm{~kg}$, and $24.3 \pm 3.0$ $\mathrm{kg} / \mathrm{m}^{2}$, respectively. Among female subjects, the corresponding values were $157.1 \pm 6.1 \mathrm{~cm}, 57.0 \pm 8.3 \mathrm{~kg}$, and 23.1 $\pm 3.4 \mathrm{~kg} / \mathrm{m}^{2}$, respectively. The mean measured FVC and $\mathrm{FEV}_{1}$ were $3.56 \pm 0.90 \mathrm{~L}$ and $2.78 \pm 0.77 \mathrm{~L}$, respectively. In male subjects, the mean measured FVC and $\mathrm{FEV}_{1}$ were $4.05 \pm 0.78 \mathrm{~L}$ and $3.09 \pm 0.76 \mathrm{~L}$, respectively. In female subjects, the corresponding values were $2.90 \pm 0.58 \mathrm{~L}$ and $2.36 \pm 0.55 \mathrm{~L}$, respectively. 
Table 1. Differences in baseline characteristics according to pulmonary function

\begin{tabular}{|c|c|c|c|}
\hline Characteristic & $\mathrm{FEV}_{1}$ or $\mathrm{FVC} \geq 140 \%$ & $\mathrm{FEV}_{1}$ and $\mathrm{FVC}<140 \%$ & $p$ value \\
\hline Number & $55(0.08)$ & $68,638(99.2)$ & \\
\hline Age, yr & $72(69-81)$ & $54(46-63)$ & $<0.001$ \\
\hline Proportion of females & $36 / 55(65.5)$ & $29,188 / 68,638(42.5)$ & 0.001 \\
\hline Weight, kg & $52.5 \pm 12.2$ & $64.5 \pm 11.5$ & $<0.001$ \\
\hline Height, cm & $148.4 \pm 11.3$ & $164.2 \pm 8.7$ & $<0.001$ \\
\hline BMI, kg/m² & $23.7 \pm 4.2$ & $23.8 \pm 3.2$ & 0.852 \\
\hline FVC, measured & $3.29 \pm 0.95$ & $3.56 \pm 0.90$ & 0.025 \\
\hline $\mathrm{FEV}_{1}$, measured & $2.65 \pm 0.72$ & $2.78 \pm 0.77$ & 0.224 \\
\hline $\mathrm{FEV}_{1} / \mathrm{FVC}, \%$ & $81 \pm 8$ & $78 \pm 10$ & 0.010 \\
\hline
\end{tabular}

Values are presented as number (\%), median (interquartile range), or mean \pm SD.

$\mathrm{FEV}_{1}$, forced expiratory volume in 1 second; FVC, forced vital capacity; BMI, body mass index.

Table 2. Incidence of high pulmonary function according to the result range

\begin{tabular}{lccc}
\hline $\begin{array}{l}\mathrm{FEV}_{1} \text { or FVC } \\
\text { predicted, \% }\end{array}$ & $\begin{array}{c}\text { Male } \\
(\mathrm{n}=19)\end{array}$ & $\begin{array}{c}\text { Female } \\
(\mathrm{n}=36)\end{array}$ & $\begin{array}{c}\text { Total } \\
(\mathrm{n}=55)\end{array}$ \\
\hline $140-149$ & $17(89.5)$ & $23(63.9)$ & $40(72.7)$ \\
$150-159$ & $1(5.3)$ & $8(22.2)$ & $9(16.3)$ \\
$160-169$ & $1(5.3)$ & $3(8.3)$ & $4(7.2)$ \\
$170-180$ & 0 & $2(5.6)$ & $2(3.6)$ \\
\hline
\end{tabular}

Values are presented as number (\%).

$\mathrm{FEV}_{1}$, forced expiratory volume in 1 second; FVC, forced vital capacity.

Table 3. Predictors of high pulmonary function according to a univariate logistic regression model

\begin{tabular}{lccr}
\hline Variable & Odds ratio & $\begin{array}{c}95 \% \text { Confidence } \\
\text { interval }\end{array}$ & p value \\
\hline Age & 1.15 & $1.12-1.18$ & $<0.001$ \\
Female sex & 2.56 & $1.47-4.47$ & 0.001 \\
Weight & 0.89 & $0.86-0.91$ & $<0.001$ \\
Height & 0.80 & $0.78-0.83$ & $<0.001$ \\
\hline
\end{tabular}

Among the 68,693 subjects, 55 (0.08\%) were classified as having a high pulmonary function (48 with high $\mathrm{FEV}_{1}$ and normal FVC, two with normal $\mathrm{FEV}_{1}$ and high FVC, and five with both high FEVı and FVC). Compared with the other subjects, those in the high pulmonary function group were significantly older ( 72 years [ 69 to 81 ] vs. 54 years [ 46 to 63$], p<0.001$ ) and more frequently female (65.5\% vs. $42.5 \%, p=0.001)$. In addition, subjects in the high pulmonary function group had a significantly low-
Table 4. Predictors of high pulmonary function by sex according to a univariate logistic regression model

\begin{tabular}{lcc}
\hline Variable & Odds ratio & 95\% Confidence interval \\
\hline Male & & $1.09-1.19$ \\
Age & 1.14 & $0.88-0.96$ \\
Weight & 0.92 & $0.72-0.81$ \\
Height & 0.76 & \\
Female & & $1.11-1.19$ \\
Age & 1.15 & $0.80-0.88$ \\
Weight & 0.84 & $0.72-0.79$ \\
\hline Height & 0.75 & \\
\hline
\end{tabular}

All variables were found to be statistically significant predictors $(p<0.001)$.

er body weight ( $52.5 \pm 12.2 \mathrm{~kg}$ vs. $64.5 \pm 11.5 \mathrm{~kg}, p<0.001)$ and shorter height $(148.4 \pm 11.3 \mathrm{~cm}$ vs. $164.2 \pm 8.7 \mathrm{~cm}, p$ $<0.001$ ) than did the others. Of these 55 subjects, most ( $\mathrm{n}=53,96.4 \%)$ had neither respiratory symptoms nor disease (PFTs were performed in 50 and three subjects for preoperative risk assessment and health screening, respectively); accordingly, no medical condition associated with a high $\mathrm{FEV}_{1}$ or FVC could be identified. Notably, the high pulmonary function group had a lower measured FVC (3.29 $\pm 0.95 \mathrm{~L}$ vs. $3.56 \pm 0.90 \mathrm{~L}, p=0.025)$ than did the other subjects (Table 1). Among subjects with a high predicted pulmonary function, those with a normal FEV1 and high FVC were younger, heavier, and taller than those with a high $\mathrm{FEV}_{1}$ and normal FVC or both a high FEV 1 and FVC (Supplementary Table 1 ).

Furthermore, 1,053 subjects (1.5\%) met the criteria for 
Table 5. Incidence of high pulmonary function according to the risk factors

\begin{tabular}{|c|c|c|}
\hline Variable & $<140 \%$ & $\geq 140 \%$ \\
\hline \multicolumn{3}{|l|}{ Male } \\
\hline \multicolumn{3}{|l|}{ Age, yr } \\
\hline$<50$ & $12,821(99.99)$ & $1(0.01)$ \\
\hline $50-65$ & 17,701 (99.99) & $2(0.01)$ \\
\hline $65-80$ & $8,295(99.87)$ & $11(0.13)$ \\
\hline$\geq 80$ & $633(99.22)$ & $5(0.78)$ \\
\hline \multicolumn{3}{|l|}{ Weight, kg } \\
\hline$<50$ & $812(99.74)$ & $2(0.26)$ \\
\hline $50-60$ & $5,099(99.87)$ & $6(0.13)$ \\
\hline $60-70$ & $14,015(99.95)$ & $7(0.05)$ \\
\hline$\geq 70$ & $19,524(99.98)$ & $4(0.02)$ \\
\hline \multicolumn{3}{|c|}{ Height, cm } \\
\hline$<150$ & $47(94.00)$ & $3(6.00)$ \\
\hline $150-160$ & $1,964(99 \cdot 54)$ & $9(0.46)$ \\
\hline $160-170$ & $17,324(99.97)$ & $6(0.03)$ \\
\hline$\geq 170$ & $20,115(99.996)$ & $1(0.004)$ \\
\hline \multicolumn{3}{|l|}{ Female } \\
\hline \multicolumn{3}{|l|}{ Age, yr } \\
\hline$<50$ & $10,957(99.96)$ & $4(0.04)$ \\
\hline $50-65$ & $12,252(99.99)$ & $1(0.01)$ \\
\hline $65-80$ & $5,524(99.64)$ & $20(0.36)$ \\
\hline$\geq 80$ & $455(97.64)$ & $11(2.36)$ \\
\hline \multicolumn{3}{|l|}{ Weight, kg } \\
\hline$<40$ & $233(96.87)$ & $7(3.13)$ \\
\hline $40-50$ & $4,835(99.65)$ & $15(0.35)$ \\
\hline $50-60$ & $14,630(99.92)$ & $11(0.08)$ \\
\hline$\geq 60$ & $9,490(99.97)$ & $3(0.03)$ \\
\hline \multicolumn{3}{|l|}{ Height, cm } \\
\hline$<140$ & $85(90.43)$ & $9(9.57)$ \\
\hline $140-150$ & $2,880(99 \cdot 34)$ & $19(0.66)$ \\
\hline $150-160$ & $15,865(99.96)$ & $6(0.04)$ \\
\hline$\geq 160$ & $10,358(99.98)$ & $2(0.02)$ \\
\hline
\end{tabular}

Values are presented as number (\%).

a high pulmonary function when defined as a predicted $\mathrm{FEV}_{1}$ or $\mathrm{FVC}$ of $\geq 120 \%$. Subjects in this high pulmonary function group were also older, more likely to be female and had a lower body weight and height when compared with the other subjects (Supplementary Table 2).

\section{Cumulative incidence of a percent predicted value of $\geq 140 \%$}

Among the 55 subjects with high pulmonary function, most $(72.7 \%)$ had a percent predicted value between $140 \%$ and $149 \%$. This group included 17 of 19 male subjects (89.5\%) and 23 of 36 female subjects (63.9\%). No subject had a value $>180 \%$ (Table 2 ).

\section{Predictors of subjects with a high percent predicted value}

To identify the predictors of a high percent predicted value, univariate logistic analysis was performed. Older age (odds ratio [OR], 1.15; 95\% confidence interval [CI], 1.12 to $1.18 ; p<0.001)$, female sex (OR, 2.56; 95\% CI, 1.47 to $4.47 ; p=0.001$ ), lower body weight (OR of weight, 0.89 ; 95\% CI, 0.86 to $0.91 ; p<0.001$ ), and shorter height (OR of height, $0.80 ; 95 \% \mathrm{CI}, 0.78$ to $0.83 ; p<0.001$ ) were found to be statistically significant predictors (Table 3). In a multivariate analysis, an older age (OR, 1.08; 95\% CI, 1.05 to $1.11 ; p<0.001$ ) and shorter height (OR of height, $0.80 ; 95 \%$ CI, 0.76 to $0.84 ; p<0.001)$ remained significant predictors of a high pulmonary function. However, multivariate analysis identified male sex, rather than female sex, as a significant predictor but failed to determine weight as a significant predictor. When men and women were analyzed separately, older age, lower body weight, and shorter height, remained significant predictors of a high pulmonary function (Table 4).

\section{Incidence of a percent predicted value of $\geq 140 \%$ according to the predictors}

Each incidence of a percent predicted value of $\geq 140 \%$ was analyzed according to sex and the identified predictors (Table 5). Regarding age, the highest incidence of high pulmonary function was observed among subjects aged $\geq 80$ years $(0.78 \%$ of male and $2.36 \%$ of female subjects). Regarding weight, a lower body weight $(<50 \mathrm{~kg}$ for men and $<40 \mathrm{~kg}$ for women) was also associated with the highest incidence of a high pulmonary function (0.26\% of men and 3.13\% of women). Regarding height, a shorter height $(<150 \mathrm{~cm}$ for men and $140 \mathrm{~cm}$ for women) yielded the same result $(6.00 \%$ of women and $9.57 \%$ of women). Among subjects who met all predictors (age > 80 years, weight $<50 \mathrm{~kg}[\mathrm{men}] / 40 \mathrm{~kg}$ [women] and height $<150 \mathrm{~cm}[\mathrm{men}] / 140 \mathrm{~cm}$ women]), 3.0\% of male subjects and $6.1 \%$ of female subjects met the criteria for the high 

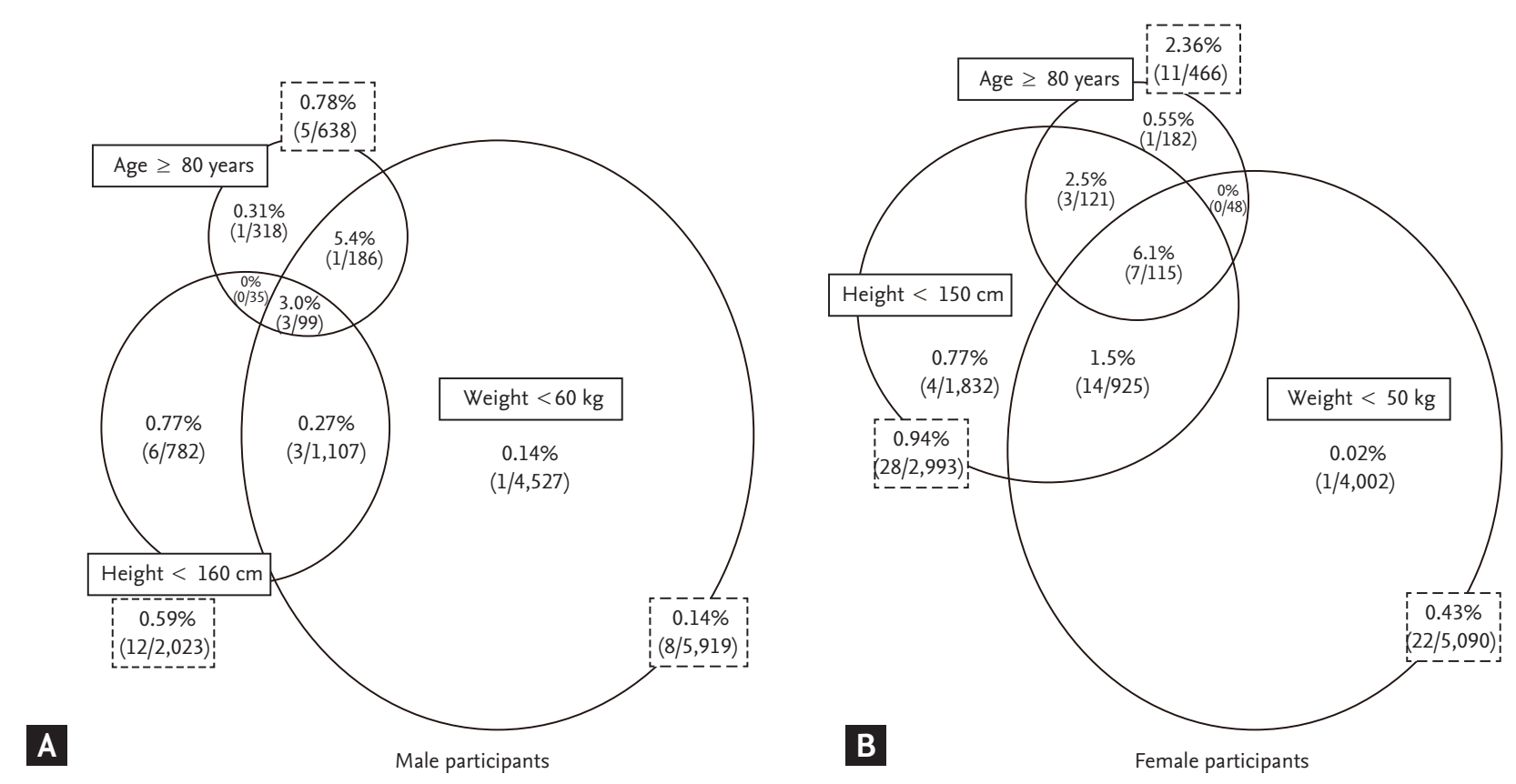

Figure 1. Proportions of subjects with high pulmonary function according to sex and the identified predictors. (A) Male and (B) female participants.

pulmonary function group (Fig. 1).

\section{DISCUSSION}

Our study found that $0.08 \%$ of the total subjects had an unusually high pulmonary function, defined as a $\mathrm{FEV}_{1}$ or $\mathrm{FVC} \geq 140 \%$ of the predicted value. This pulmonary function pattern was more common in older ( $>80$ years) female participants with a lower body weight $(<50 \mathrm{~kg})$ and shorter height $(<140 \mathrm{~cm})$. An unusually high pulmonary function was not rare in this specific population (6.1\%). Furthermore, an older age and shorter height remained significant predictors of a high pulmonary function in multivariate analysis.

The PFT plays an important role in the diagnosis and management of respiratory diseases [9,10]. Because the PFT results depend on height, age, sex, and ethnicity, standardization and development of correct reference equations using "local healthy controls" are critical issues $[8,11]$. As noted above, the reference equations were derived using cross-sectional data from representative populations [12-16], indicating a requirement for sufficient numbers of participants in each age, sex, height, and weight category. However, it is not possible to col- lect sufficient data from all populations, particularly individuals with unusual heights or body weights. Therefore, the values generated using prediction equations may differ from the observed values in some minority populations [8], and this limitation should be considered when interpreting such data. The Korean reference equation was developed using data from 1,212 nonsmokers to provide a better local standard [7]. However, although data from more than 1,00o people were used to derive the reference equation, the subject group included only nine subjects older than 70 years [7]. This situation is consistent with that associated with the development of other reference equations; in a British study, only $6 \%$ of male and $9 \%$ of female subjects were older than 75 years [13], whereas several other previous studies included no subjects older than 65 years $[14,17,18]$. Our data suggest that reference values for elderly populations may be inaccurate and that a wider range of populations is needed to avoid under- or over-estimation of spirometry results.

Only a few previous studies have analyzed high PFT results. In swimmers, a relatively higher pulmonary function was associated with increases in the chest wall width and muscle strength [19,20]. Cochet et al. [21] found that $5.5 \%$ of all patients had either a FEV or FVC > $110 \%$ 
of the predicted value, whereas $1.5 \%$ of the patients had an $\mathrm{FEV}_{1}$ or $\mathrm{FVC}>120 \%$ of the predicted value; furthermore, the proportion of patients with supranormal lung function did not differ significantly between active duty military personnel and a non-active duty population of the same age range. However, even these studies did not mention patients with unusually high PFT results ( $\geq$ $140 \%$ of the predicted value), and only one suggestion was made to re-check the calibration and demographic data in such cases [5]. This guidance is partly reasonable because the cases with values $\geq 140 \%$ of the predicted value are very rare in the general population. Only one (0.004\%) of 20,115 male subjects with a height $>170 \mathrm{~cm}$ had a value $\geq 140 \%$ of the predicted value. Similarly, only one (0.01\%) of 12,821 male subjects aged younger than 50 years had an abnormally high value (Table 5). However, we note that such values were not rare in some specific demographic groups, such as short elderly women.

In our study, old age was associated with a high predicted pulmonary function. Increasing age corresponds with decreases in the static elastic recoil of the lung, chest wall compliance and respiratory muscle strength [22]. In humans, the $\mathrm{FEV}_{1}$ and FVC generally increase up to the middle of the third decade of life, then decrease thereafter $[23,24]$. However, physiologic measurements vary more widely among older populations, compared with younger populations [25]. Indeed, age was not normally distributed (Kolmogorov-Smirnov test, $p=0.032$; histogram in Fig. 2) among 55 subjects with high pulmonary function. Although subjects with a high pulmonary function tended to be older, many previous reference equations were based on extrapolations about minority populations, especially those older than 70 years $[7,13-$ $15,26]$. Given the expected global increase in life expectancy [27], a reference equation that has been validated in a sufficiently large population of older subjects is essential.

Although female sex was a significant predictor of a high pulmonary function in the univariate analysis, male sex was associated with a high pulmonary function after adjusting for age, height, and weight. This conflicting result might be attributable to the small number of subjects with high pulmonary function and an imbalance of anthropometric values between female and male subjects. Indeed, within the high pulmonary function group, female subjects had a lower weight (47.6

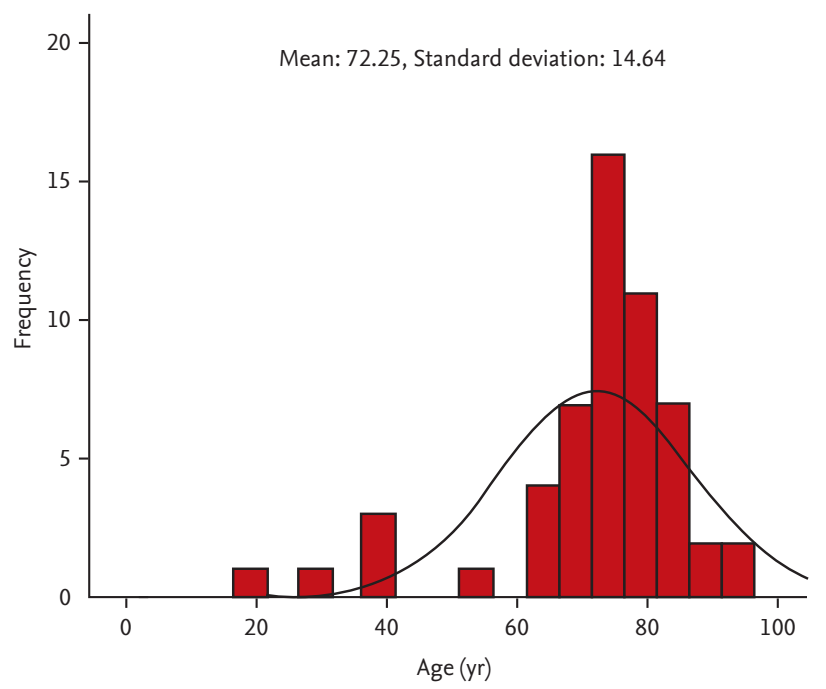

Figure 2. Histogram of the age distribution among subjects with high pulmonary function.

kg vs. $61.8 \mathrm{~kg}, p<0.001)$ and shorter height $(143.9 \mathrm{~cm}$ vs. $157.0 \mathrm{~cm}, p<0.001$ ) than did the men, and this imbalance might have affected our results. In addition, although height was a significant predictor of a high pulmonary function in both the univariate and multivariate analyses, body weight was only significant in the former, which suggests that height might be a stronger predictor of pulmonary function. As the body weight correlated positively with height $(r=0.641, p<0.001)$, the former parameter might lose significance in a multivariate analysis including the latter.

This study has several limitations of note. First, the design was retrospective in nature. However, we included a large number of patients with little missing data. Furthermore, we included all subjects who underwent PFT during a single calendar year to minimize confounding factors. Second, our analysis included only patients at a single referral center in South Korea. Third, only 55 subjects (0.08\% of all included subjects) were found to have high pulmonary function and thus it is difficult to generalize the results of our current study. External validation studies in other populations of subjects may be necessary.

In summary, an unusually high PFT was associated with the female sex, an older age, lower body weight and shorter height, and this outcome was not unusual among subjects who exhibited all of these characteristics. Therefore, we should consider the demographics 
of the examinees and the limitations of reference equations when interpreting PFT results. The meticulous inclusion of various healthy controls when generating reference equations may reduce this type of overestimation.

\section{KEY MESSAGE}

1. A high predicted pulmonary function pattern was more common among older participants with a lower body weight and shorter height.

2. The reference equations derived from representative population may not be correct in some minority.

\section{Conflict of interest}

No potential conflict of interest relevant to this article was reported.

\section{Acknowledgements}

This study was supported by grants (2014-613 and 20180352) from the Asan Institute for Life Sciences, Asan Medical Center, Seoul, Korea.

\section{REFERENCES}

1. Ranu H, Wilde M, Madden B. Pulmonary function tests. Ulster Med J 2011;80:84-90.

2. Datta D, Lahiri B. Preoperative evaluation of patients undergoing lung resection surgery. Chest 2003;123:20962103.

3. Global Initiative for Chronic Obstructive Lung Disease. GOLD 2017 global strategy for the diagnosis, management and prevention of chronic obstructive pulmonary disease [Internet]. Fontana (WI): Global Initiative for Chronic Obstructive Lung Disease, c2019 [cited 2019 Sep 6]. Available from: http://goldcopd.org/gold-2017-global-strategy-diagnosis-management-prevention-copd/.

4. Global Initiative for Asthma. 2019 GINA report, global strategy for asthma management and prevention [Internet]. Fontana (WI): Global Initiative for Asthma, c2019 [cited 2019 Sep 6]. Available from: https://ginasthma.org/ archived-reports/.

5. Centers for Disease Control and Prevention. Niosh spi- rometry training guide [Internet]. Atlanta (GA): CDC, 2003 [cited 2019 Sep 6]. Available from: https://www.cdc. gov/niosh/docs/2004-154c/.

6. Hankinson JL, Odencrantz JR, Fedan KB. Spirometric reference values from a sample of the general U.S. population. Am J Respir Crit Care Med 1999;159:179-187.

7. Choi JK, Paek D, Lee JO. Normal predictive values of spirometry in Korean population. Tuberc Respir Dis 2005;58:230-242.

8. Miller MR, Hankinson J, Brusasco V, et al. Standardisation of spirometry. Eur Respir J 2005;26:319-338.

9. Han MK, Kim MG, Mardon R, et al. Spirometry utilization for COPD: how do we measure up? Chest 2007;132:403-409.

10. Gershon AS, Victor JC, Guan J, Aaron SD, To T. Pulmonary function testing in the diagnosis of asthma: a population study. Chest 2012;141:1190-1196.

11. Quanjer PH, Stocks J, Cole TJ, Hall GL, Stanojevic S; Global Lungs Initiative. Influence of secular trends and sample size on reference equations for lung function tests. Eur Respir J 2011;37:658-664.

12. American Thoracic Society. Lung function testing: selection of reference values and interpretative strategies. Am Rev Respir Dis 1991;144:1202-1218.

13. Falaschetti E, Laiho J, Primatesta P, Purdon S. Prediction equations for normal and low lung function from the Health Survey for England. Eur Respir J 2004;23:456-463.

14. Boskabady MH, Keshmiri M, Banihashemi B, Anvary $\mathrm{K}$. Lung function values in healthy non-smoking urban adults in Iran. Respiration 2002;69:320-326.

15. Dejsomritrutai W, Wongsurakiat P, Chierakul N, Charoenratanakul S, Nana A, Maranetra KN. Comparison between specified percentage and fifth percentile criteria for spirometry interpretation in Thai patients. Respirology 2002;7:123-127.

16. Baur X, Isringhausen-Bley S, Degens P. Comparison of lung-function reference values. Int Arch Occup Environ Health 1999;72:69-83.

17. Standardized lung function testing. Report working party. Bull Eur Physiopathol Respir 1983;19 Suppl 5:1-95.

18. Paoletti P, Pistelli G, Fazzi P, et al. Reference values for vital capacity and flow-volume curves from a general population study. Bull Eur Physiopathol Respir 1986;22:451459.

19. Vaccaro P, Clarke DH, Morris AF. Physiological characteristics of young well-trained swimmers. Eur J Appl Physiol Occup Physiol 1980;44:61-66. 
20. Armour J, Donnelly PM, Bye PT. The large lungs of elite swimmers: an increased alveolar number? Eur Respir J 1993;6:237-247.

21. Cochet AA, Lucero PF, Zacher LL, Morris MJ. Prevalence of supranormal pulmonary function test values between a military and nonmilitary cohort. Respir Care 2014;59:749755 .

22. Zeleznik J. Normative aging of the respiratory system. Clin Geriatr Med 2003;19:1-18.

23. Knudson RJ, Slatin RC, Lebowitz MD, Burrows B. The maximal expiratory flow-volume curve. Normal standards, variability, and effects of age. Am Rev Respir Dis 1976;113:587-600.
24. Janssens JP, Pache JC, Nicod LP. Physiological changes in respiratory function associated with ageing. Eur Respir J 1999;13:197-205.

25. Sharma G, Goodwin J. Effect of aging on respiratory system physiology and immunology. Clin Interv Aging 2006;1:253-260.

26. Kotaniemi JT, Kataja M. Spirometry values in adults in northern Finland. Int J Circumpolar Health 2004;63:129139.

27. Kontis V, Bennett JE, Mathers CD, Li G, Foreman K, Ezzati M. Future life expectancy in 35 industrialised countries: projections with a Bayesian model ensemble. Lancet 2017;389:1323-1335. 
Supplementary Table 1. Differences in baseline characteristics according to pulmonary function

\begin{tabular}{lccc}
\hline Characteristic & Only FVC $\geq 140 \%$ & Only FEV $_{1} \geq 140 \%$ & FEV $_{1}$ and FVC $\geq 140 \%$ \\
\hline Number & 2 & 48 & 5 \\
Age, yr & $43(\mathrm{NA})$ & $76(71-81)$ & $69(41-76)$ \\
Proportion of females & 0 & $31(64.6)$ & $5(100.0)$ \\
Weight, kg & $66.4 \pm 6.2$ & $52.8 \pm 11.9$ & $44.0 \pm 12.1$ \\
Height, cm & $168.5 \pm 0.7$ & $148.5 \pm 9.4$ & $139.4 \pm 19.6$ \\
BMI, kg/m ${ }^{2}$ & $23.4 \pm 2.4$ & $23.8 \pm 4.5$ & $22.3 \pm 1.0$ \\
FVC, measured & $5.33 \pm 0.41$ & $3.21 \pm 0.88$ & $3.23 \pm 1.02$ \\
FEV $_{1}$, measured & $3.55 \pm 1.24$ & $2.62 \pm 0.69$ & $2.53 \pm 0.82$ \\
FEV $_{1} /$ FVC, $\%$ & $66.0 \pm 18.4$ & $82.3 \pm 7.7$ & $78.6 \pm 5.8$ \\
\hline
\end{tabular}

Values are presented as median (interquartile range), number (\%), or mean $\pm \mathrm{SD}$.

FVC, forced vital capacity; FEVı, forced expiratory volume in 1 second; NA, not available; BMI, body mass index. 
Chang $Y$, et al. Lung function in small elderly subjects

Supplementary Table 2. Differences in baseline characteristics according to pulmonary function

\begin{tabular}{|c|c|c|c|}
\hline Characteristic & $\mathrm{FEV}_{1}$ or $\mathrm{FVC} \geq 120 \%$ & $\mathrm{FEV}_{1}$ and $\mathrm{FVC}<120 \%$ & $p$ value \\
\hline Number & $1,053(1.5)$ & $67,640(98.5)$ & \\
\hline Age, yr & $72(69-81)$ & $54(46-63)$ & $<0.001$ \\
\hline Proportion of females & $36 / 55(65 \cdot 5)$ & $29,188 / 68,638(42.5)$ & 0.001 \\
\hline Weight, kg & $59.2 \pm 10.2$ & $64.6 \pm 11.5$ & $<0.001$ \\
\hline Height, cm & $158.4 \pm 10.1$ & $164.4 \pm 8.7$ & $<0.001$ \\
\hline $\mathrm{BMI}, \mathrm{kg} / \mathrm{m}^{2}$ & $23.5 \pm 2.9$ & $23.8 \pm 3.2$ & 0.005 \\
\hline FVC, measured & $4.01 \pm 1.09$ & $3.56 \pm 0.90$ & $<0.001$ \\
\hline $\mathrm{FEV}_{1}$, measured & $3.18 \pm 0.86$ & $2.77 \pm 0.76$ & $<0.001$ \\
\hline $\mathrm{FEV}_{1} / \mathrm{FVC}, \%$ & $80 \pm 9$ & $78 \pm 10$ & $<0.001$ \\
\hline
\end{tabular}

Values are presented as number (\%), median (interquartile ranges), or mean $\pm \mathrm{SD}$.

$\mathrm{FEV}_{1}$, forced expiratory volume in 1 second; FVC, forced vital capacity; BMI, body mass index. 